\title{
Senescence of Rice Leaves XVIII. Changes of Stomatal Aperture during Senescence
}

\author{
Weei Piring Hurng ${ }^{1,4}$, T'ai Lang Lin $^{2}$, Shau Shi Ren ${ }^{2}$, Jia Chyuan Chen ${ }^{3}$, \\ Yung Reui Chen ${ }^{2}$ and Ching Huei Kao ${ }^{1,5}$ \\ 1 Department of Agronomy, National Taiwan University, Taipei, Taiwan, Republic of China \\ ${ }^{2}$ Department of Botany, National Taiwan University, Taipei, Taiwan, Republic of China \\ ${ }^{3}$ Department of Zoology, National Taiwan University, Taipei, Taiwan, Republic of China
}

\begin{abstract}
Changes of stomatal aperture during the course of development of rice leaves were directly observed with a scanning electron microscope. The stomata reached their maximal aperture size after senescence began in seedling leaves and the flag leaf of mature plants. The small stomatal aperture observed prior to senescence seems to be the normal size of stomata in rice leaves, and thus stomata closure does not seem to be the cause of leaf senescence in rice plants. The stomata retain their capability of movement during senescence, suggesting that guard cells tend to live longer than mesophyll cells.
\end{abstract}

Key words: Leaf senescence - Oryza sativa - Stomatal aperture.

Kasamo (1976) reported that the effect of kinetin on the senescence of tobacco leaf discs was decreased or nearly nullified when the epidermis was peeled off. Kuraishi (1976) also showed that Chl retention was severely inhibited by coating the leaf surface with vaseline either in the presence or absence of kinetin. Thimann and Satler (1979a, b) demonstrated that leaf senescence was strongly delayed by the treatments that caused the stomata to open and strongly promoted by those that caused them to close. Friedrich and Huffaker (1980) measured twelve physiological parameters during senescence of barley primary leaves and found that stomatal resistance changed more dramatically and rapidly than any other parameter. These findings seem to suggest that stomatal aperture causes leaf senescence.

To find whether this hypothesis can be applied to the rice system, the stomatal aperture was directly observed using a scanning electron microscope during the senescence of rice leaves.

\section{Materials and Methods}

Plant material-Rice (Oryza sativa L. cv. Taichung Native 1) seedlings were grown as previously described

\footnotetext{
$\overline{4}$ Present address: Tobacco Research Institute, Taichung, Taiwan, Republic of China

${ }^{s}$ To whom reprint requests should be addressed.
}

(Cheng and Kao 1984). Briefly, seedlings were planted on a stainless net floating on half-strength Johnson's modified nutrient solution (Johnson et al. 1957) in a 500-ml beaker. The nutrient solution ( $\mathrm{pH} 4.5$ ) was replaced every three days. Rice seedlings were grown in a greenhouse with natural day light at $30^{\circ} \mathrm{C}$ day $/ 25^{\circ} \mathrm{C}$ night and humidity $95 \%$. Leaf samples ( $3 \mathrm{~cm}$ from tip) were collected from the third leaves of seedlings at $8,10,12,14,16,18$ and 20 days after planting. For the experiments in which mature leaves of rice plants were used, rice plants were grown in pots $\left(2 \mathrm{dm}^{2}\right)$ containing sandy loam in a greenhouse under the same conditions as in the seedling experiment. Each pot received $\mathrm{N}, \mathrm{P}, \mathrm{K}$ at a rate of $1 \mathrm{~g}$, respectively, at sowing. Samples of flag leaf were collected from the time when $\mathrm{Chl}$ content reached maximal level (about 87 days after planting) to 132 days after planting. The changes in the content of $\mathrm{Chl}$ and/or protein were used as a senescence index in all experiments.

$\mathrm{Chl}$ and protein determinations-Chl in the leaves of seedlings was extracted with $80 \%$ ethanol and determined as described elsewhere (Kao 1980), and it is expressed as $A_{665}$ per ten segments. The $\mathrm{Chl}$ content of the flag leaf was measured by the method of Arnon (1949) and expressed as $\mathrm{mg} \mathrm{Chl} \mathrm{per} \mathrm{g}$ fresh weight. Protein was determined by the method of Lowry et al. (1951) and expressed as $A_{700}$ per ten segments.

Scanning electron microscopy-Leaves were fixed at 9 a.m. every sampling day. Intact leaves were immersed in 
$3 \%(\mathrm{v} / \mathrm{v})$ glutaraldehyde in $0.1 \mathrm{M}$ sodium cacodylate at pH 7.0 for $3 \mathrm{~min}$ after which leaves were cut into sections less than $1 \mathrm{~mm}$ thick. Sections were then fixed in the same buffer solution for $2 \mathrm{~h}$. Fixed sections were rinsed twice with cacodylate buffer $(0.1 \mathrm{M}, \mathrm{pH} 7.0)$ containing $5 \%$ sucrose and post-fixed in $1 \%(\mathrm{w} / \mathrm{v})$ osmium tetraoxide in the same buffer for $2 \mathrm{~h}$. Sections were rinsed again, dehydrated in graded ethanol series and $100 \%$ acetone, and dried at the critical point. Dried sections were coated with gold using an Eiko Engineering IB-2 Ion Sputter Coater. All observations were made with a Hitachi S-520 scanning electron microscope. The average stomatal width of the third leaves was estimated from 10 photographs of stomata.

Measurement of diffusion resistance-For the flag leaf, stomatal aperture was also measured by the diffusion porometer (Lambda Instruments LI-1600). Difusion resistance was expressed as $\mathrm{sec} / \mathrm{cm}$.

\section{Results}

The senescence of rice leaves was followed by measuring the decrease in $\mathrm{Chl}$ and protein or Chl only. To study the changes in stomatal aperture during reproductive development, the flag leaf of the plants grown in the greenhouse was used. The initial time points in Fig. 1 (87 days after planting) represent the flag leaf fully expanded, which had maximal $\mathrm{Chl}$ content. Total $\mathrm{Chl}, \mathrm{Chl}$ a and $\mathrm{Chl} \mathrm{b}$ decreased steadily in the flag leaf during reproductive development. Using the scanning electron microscope, we directly observed the stomata on both adaxial and abaxial

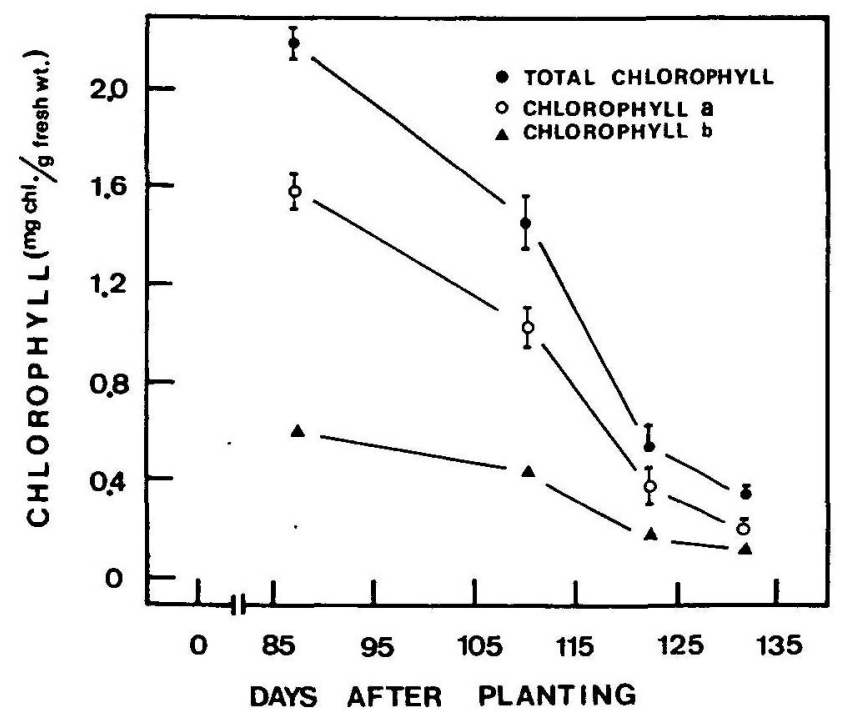

Fig. 1 Changes of total $\mathrm{Chl}, \mathrm{Chl} \mathrm{a}$ and $\mathrm{Chl} b$ in flag leaf of rice plants during reproductive development. Vertical bars represent $\pm \mathrm{SE}$.
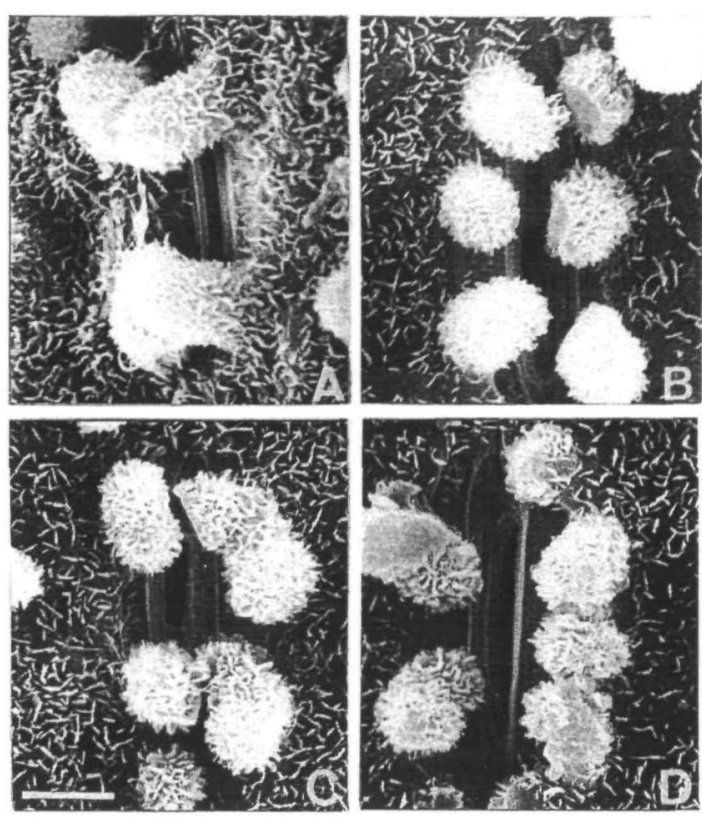

Fig. 2 Typical scanning electron micrographs showing the stomatal aperture on the adaxial surface of flag leaf of 87 (A), 110 (B), 122 (C) and 132 (D) days after planting. Bar represents $3 \mu \mathrm{m}$.
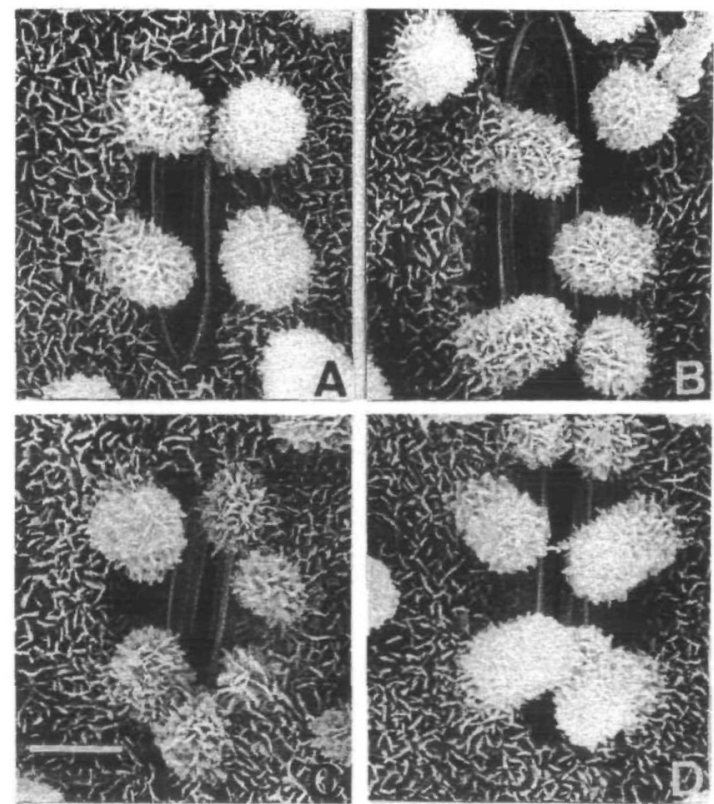

Fig. 3 Typical scanning electron micrographs showing the stomatal aperture on the abaxial surface of flag leaf of 87 (A), 110 (B), 122 (C) and 132 (D) days after planting. Bar represents $3 \mu \mathrm{m}$. 


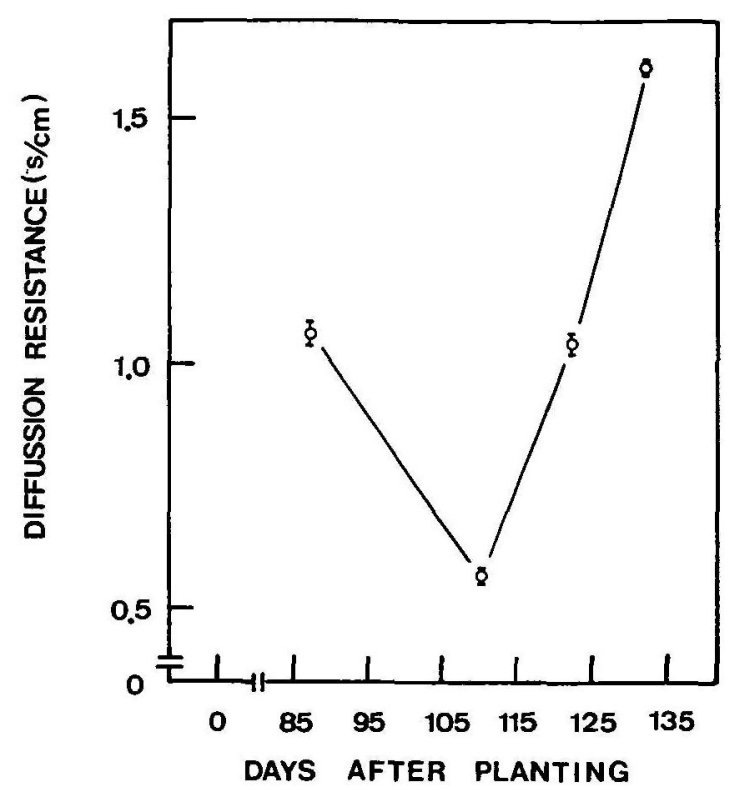

Fig. 4 Changes of diffusion resistance of flag leaf during reproductive development.

surfaces of flag leaf. The stomata of both adaxial and abaxial surfaces had small apertures when the flag leaf was fully expanded at 87 days after planting (Fig. 2 and 3). During the senescence of the flag leaf, the stomatal aper-

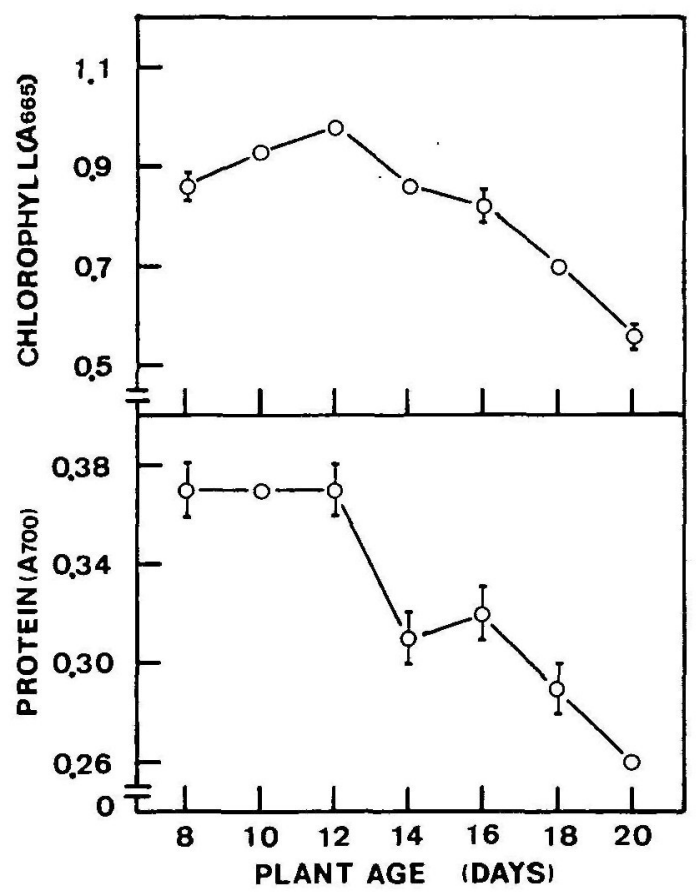

Fig. $5 \mathrm{Chl}$ and protein contents in the third leaf of rice seedlings during senescence. Vertical bars represent \pm SE.

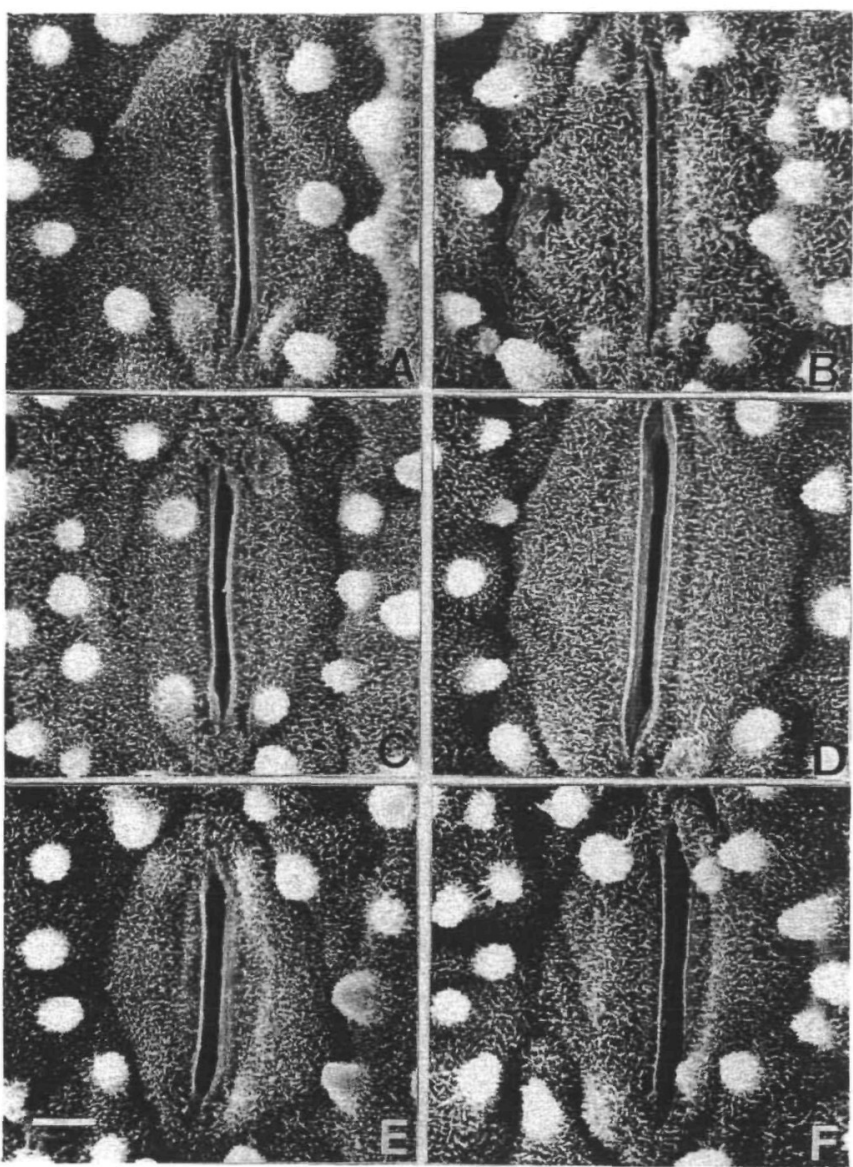

Fig. 6 Typical scanning electron micrographs showing the stomatal aperture on the adaxial surface of the third leaf of 8- (A), 10- (B), 12- (C), 14- (D), 18- (E) and 20-day-old (F) rice seedlings. Bar represents $3 \mu \mathrm{m}$.

ture first increased and then decreased steadily. The changes in the stomatal aperture observed with the scanning electron microscope coincided closely with those of

Table 1 Average width of stomata on the adaxial surface of the third leaf of rice seedlings

\begin{tabular}{cc}
\hline Days after planting & Average width $(\mu \mathrm{m})$ \\
\hline 8 & $0.21 \pm 0.02$ \\
10 & $0.18 \pm 0.01$ \\
12 & $0.21 \pm 0.03$ \\
14 & $0.54 \pm 0.05$ \\
18 & $0.62 \pm 0.02$ \\
20 & $0.60 \pm 0.04$ \\
\hline
\end{tabular}

Width is expressed in $\mu \mathrm{m} \pm \mathrm{SE}$. 


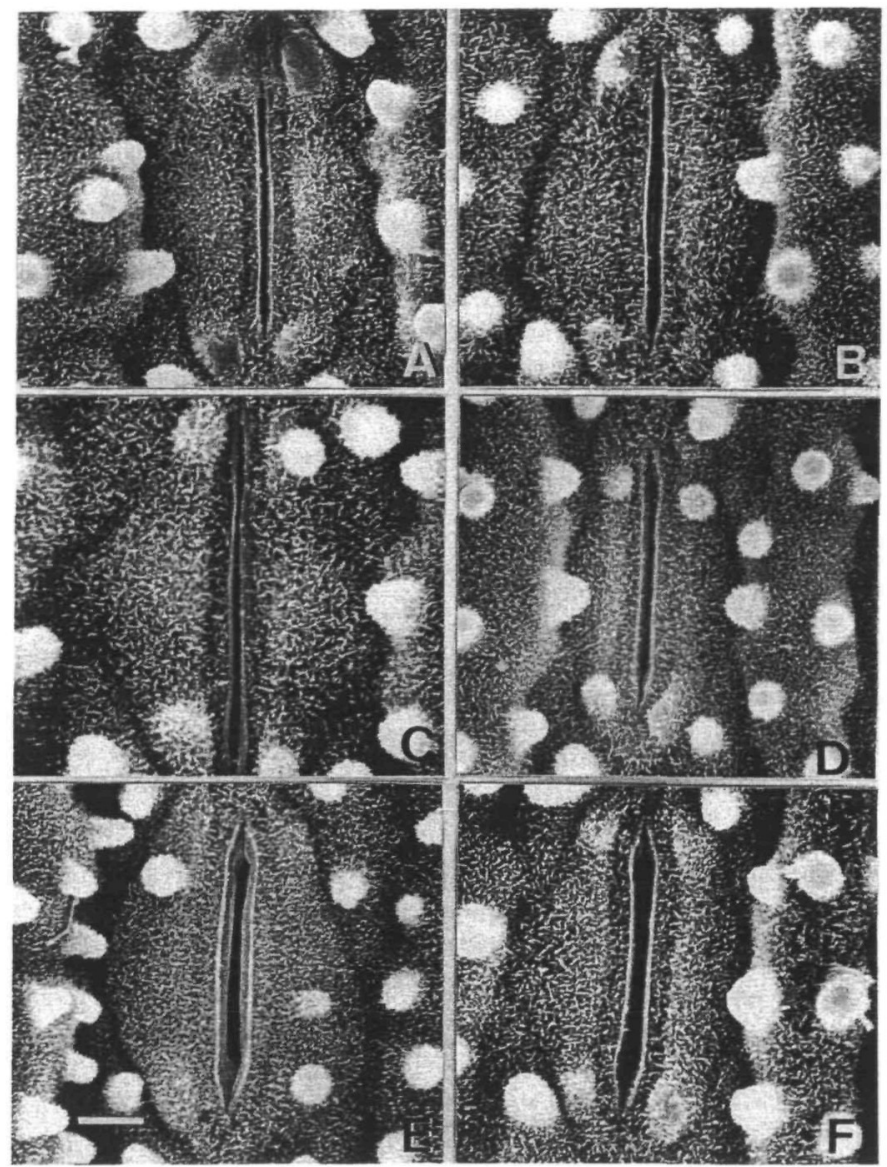

Fig. 7 Typical scanning electron micrographs showing the stomatal aperture on the abaxial surface of the third leaf of 8(A), 10- (B), 12- (C), 14- (D), 16- (E), and 20-day-old (F) seedlings. Bar represents $3 \mu \mathrm{m}$.

diffusion resistance, measured by the diffusion porometer, of the flag leaf during reproductive development (Fig. 4), suggesting that the stomatal aperture findings observed with the scanning electron microscope were reliable. The fully expanded flag leaf displayed high diffusion resistance. During senescence of the flag leaf, the diffusion resistance first decreased and then increased dramatically, indicating that the stomata in the senescing flag leaf retained the capability of movement.

The levels of $\mathrm{Chl}$ and protein in the third leaf from 8to 20-day-old seedlings are shown in Fig. 5. Chl increased up to 12 days after planting and subsequently declined. However, protein remained unchanged between days 8 to 12 and then decreased progressively with age. These results indicate that senescence of the third leaf of rice seedlings was taking place during days 12 to 20 . Fig. 6 and Table 1 show the changes of the aperture of adaxial stomata of seedling leaves during senescence. The aper-
Table 2 Average width of stomata on the abaxial surface of the third leaf of rice seedlings

\begin{tabular}{cc}
\hline Days after planting & Average width $(\mu \mathrm{m})$ \\
\hline 8 & $0.15 \pm 0.01$ \\
10 & $0.18 \pm 0.04$ \\
12 & $0.15 \pm 0.03$ \\
14 & $0.15 \pm 0.06$ \\
16 & $0.61 \pm 0.02$ \\
20 & $0.60 \pm 0.03$
\end{tabular}

Width is expressed in $\mu \mathrm{m} \pm \mathrm{SE}$.

ture of the adaxial stomata was generally smaller during days 8 to 12 than that during days 14 to 20 , suggesting that the stomatal aperture is smaller prior to senescence and the stomata retain the capability of movement during senescence. This also seems to occur with the stomata on the abaxial surface as shown in Fig. 7 and Table 2.

\section{Discussion}

Stomata of senescing leaves generally open significantly less than those of nonsenescing leaves (Davis and McCree 1978, Ludlow and Wilson 1971, Vaclavik 1973). However, our results shows that stomata reached their maximal aperture size after senescence began in seedling leaves and flag leaf of rice plants. Although the aperture size of adaxial and abaxial stomata in seedlings leaves is generally small prior to senescence, the small stomatal aperture observed prior to senescence seems to be the normal size of stomata in rice leaves. This simply because that stomata in 8-day-old seedling leaves, which are very young, had aperture sizes similar to those in 12-day-old sedling leaves. Furthermore, the aperture size of stomata in fully expanded flag leaf (87 days after planting) does not differ much from that in young seedling leaves. Based on foregoing considerations, we concluded that the stomata closure does not seem to be the cause of leaf senescence in rice plants. This conclusion does not agree with the the suggestion made by other investigators (Kasamo 1976, Kuraishi 1976, Thimann and Satler 1979a, b, Friedrich and Huffaker 1980), who suggested that stomatal aperture plays a pivotal role in regulating leaf senescence.

Zeiger and Schwartz (1982) suggested that yellowing leaves retain stomatal control throughout the senescence process. This is consistent with our finding that stomata are capable of movement during leaf senescence. In other words, guard cells of senescing leaves do exhibit signs of functionality. Peoples et al. (1980) compared the longevity of guard cells and mesophyll cells of wheat leaves and found that guard cells tended to retain more intact 
organelles and membranes than mesophyll cells when the senescence was well advanced. Leaf senescence is characterized by the orderly, progressive disassembly of mesophyll cells. It seems that guard cells, unlike mesophyll cells, do not undergo orderly senescence.

This research was supported by a grant from the National Science Council of the Republic of China.

\section{References}

Arnon, D. I. (1949) Copper enzymes in chloroplasts. Polyphenoloxidase in Beta vulgaris. Plant Physiol. 24: 1-15.

Cheng, S. H. and Kao, C. H. (1984) The role of proteolytic enzymes in protein degradation during senescence of rice leaves. Physiol. Plant. 62: 231-237.

Davis, S. S. and McCree, K. J. (1978) Photosynthetic rate and difussion conductance as a function of age in leaves of the bush bean (Phaseolus vulgaris L). Crop Sci. 18: 280-282.

Friedrich, J. W. and Huffaker, R. C. (1980) Photosynthesis, leaf resistance, and ribulose-1,5-bisphosphate carboxylase degradation in senescing barley leaves. Plant Physiol. 65: 1103-1107.

Johnson, C. M., Stout, P. R., Broyer, T. C. and Carlton, A. B. (1957) Comparative chlorine requirements of different plant species. Plant Soil 8: 337-353.

Kao, C. H. (1980) Senescence of rice leaves IV. Influence of benzyladenine on chlorophyll degradation. Plant Cell Physiol. 21: 1255-1262.
Kasamo, K. (1976) The role of the epidermis in kinetin-induced retardation of chlorophyll degradation in tobacco leaf discs during senescence. Plant Cell Physiol. 17: 1297-1307.

Kuraishi, S. (1976) Ineffectiveness of cytokinin-induced chlorophyll retention in hypostomatous leaf discs. Plant Cell Physiol. 17: 875-885.

Lowry, O. H., Rosebrough, N. J., Farr, S. L. and Randall, R. J. (1951) Protein measurement with the folin phenol reagent. $J$. Biol. Chem. 193: 265-275.

Ludlow, M. M. and Wilson, G. L. (1971) Photosynthesis of tropical pasture plants III. Leaf age. Aust. J. Biol. Sci. 24: 1077-1087.

Peoples, M. B., Beilharz, V.C., Waters, S. P., Simpson, R. J. and Dalling, M. J. (1980) Nitrogen redistribution during grain growth in wheat (Triticum aestivum L.) II. Chloroplast senescence and the degradation of ribulose-1,5-bisphosphate carboxylase. Planta 149: 241-251.

Thimann, K. V. and Satler, S. (1979a) Relation between senescence and stomatal opening: senescence in light. Proc. Natl. Acad. Sci. USA 76: 2295-2298.

Thimann, K. V. and Satler, S. (1979b) Relation between senescence and stomatal opening: senescence in darkness. Proc. Natl. Acad. Sci. USA 76: 2770-2773.

Vaclavik, J. (1973) Effect of different leaf ages on the relationship between the $\mathrm{CO}_{2}$ uptake and water vapor efflux in tobacco plants. Biol. Plant. 15: 233-236.

Zeiger, E. and Schwartz, A. (1982) Longevity of guard cell chloroplasts in falling leaves: implication for stomatal function and cellular aging. Science 218: 680-682.

(Received March 12, 1987; Accepted September 30, 1987) 